\title{
Evaluation of Flip-Flop Jet Nozzles for Use as Practical Excitation Devices
}

Ganesh Raman

NYMA, Inc.

Engineering Services Division

Brook Park, Ohio

Edward J. Rice

National Aeronautics and Space Administration

Lewis Research Center

Cleveland, Ohio

and

David M. Cornelius

Stanford University

Stanford, California

Prepared for the ASME Fluids Engineering Division Summer Meeting sponsored by the American Society of Mechanical Engineers Lake Tahoe, Nevada, June 19-23, 1994

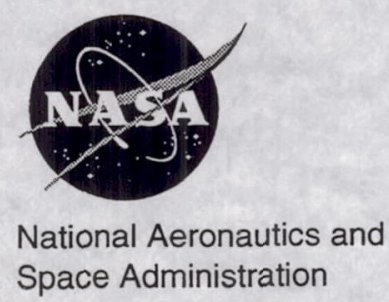

Space Administration 


\title{
EVALUATION OF FLIP-FLOP JET NOZZLES FOR USE AS PRACTICAL EXCITATION DEVICES
}

\author{
Ganesh Raman \\ NYMA, Inc. \\ Engineering Services Division \\ Brook Park, Ohio 44142 \\ Edward J. Rice ${ }^{1}$ \\ National Aeronautics and Space Administration \\ Lewis Research Center \\ Cleveland, Ohio 44135 \\ and \\ David M. Cornelius ${ }^{2}$ \\ Stanford University \\ Department of Aeronautics and Astronautics \\ Stanford, California 94305
}

\begin{abstract}
This paper describes the flowfield characteristics of the flip-flop jet nozzle and the potential for using this nozzle as a practical excitation device. It appears from the existing body of published information that there is a lack of data on the parameters affecting the operation of such nozzles and on the mechanism of operation of these nozzles. An attempt is made in the present work to study the important parameters affecting the operation and performance of a flip-flop jet nozzle. Measurements were carried out to systematically assess the effect of varying the nozzle pressure ratio (NPR) as well as the length and volume of the feedback tube on the frequency of oscillation of this device. Flow visualization was used to obtain a better understanding of the jet flowfield and of the processes occurring within the feedback tube. The frequency of oscillation of the flip-flop jet depended significantly on the feedback tube length and volume as well as on the nozzle pressure ratio. In
\end{abstract}

contrast, the coherent velocity perturbation levels did not depend on the above mentioned parameters. The data presented in this paper would be useful for modeling such flip-flop excitation devices that are potentially useful for controlling practical shear flows.

\section{INTRODUCTION}

Although evidence of the use of fluid power dates back to ancient civilization (Tokaty (1971), Morris (1973)), only recently has significant progress been made in the development of control devices that do not use moving parts, for example; turbulence amplifiers, wall attachment devices, active and passive momentum interaction devices, and vortex devices (see Morris (1973)). In the 1970's fluid control techniques were applied to jet nozzles in a pioneering paper on "flip-flop jet nozzles" by Viets (1975) and Viets et al. (1975a). Despite all the work that exists in this area, the understanding of the operation of such devices is far from complete.

\footnotetext{
${ }^{1}$ NASA Lewis Distinguished Research Associate, retired.

${ }^{2}$ Summer Student Intern at NASA Lewis Research Center.
} 
The potential for using flip-flop jets for the control of practical shear flows is the driving force behind the present investigation. Methods such as acoustic excitation (Crow and Champagne (1971), Ahuja et al. (1982), Raman and Rice (1991)) used for controlling shear flows in fundamental research experiments are not likely to be effective under practical conditions. In recent years a variety of novel fluid flow control devices have been developed. Examples of such devices are the whistler nozzle (Hill and Greene (1977)), tabs at the jet exit (Ahuja and Brown (1989), Zaman et al. (1994)), suction at the jet exit periphery (Strykowski et al. (1992)) and transverse injection using auxiliary jets (Davis (1982)). Other recent concepts include bifurcating jets (Parekh et al. (1987)), hydrodynamic excitation (Brown and Ahuja (1990)), the use of piezoelectric actuators (Wiltse and Glezer (1993)) and the use of artificially induced screech (Rice and Raman (1993)). The flip-flop jet provides yet another possibility for the control of practical flows. In pursuit of the above goal there has been a recent renewal of interest in flip-flop jets (Schreck (1992), Raman et al. (1993) and Raman and Rice (1993)). Other applications of flip-flop jets such as in two-phase flow (Morris et al. (1992)) and in foam spreading (Viets et al. (1975b)) have also been reported.

The parameters affecting the operation of a bistable fluid amplifier and a wall attachment fluidic oscillator were studied by Warren (1962) and Beale and Lawyer (1974), respectively. Subsequent work by Viets (1975) and Viets et al. (1975a) suggested that the nozzle pressure ratio as well as feedback tube length and volume played a role in determining the frequency of the flip-flop jet, but no clear relationships were established. The objective of the present work is to study the effect of the nozzle pressure ratio $(\mathrm{NPR}=$ ratio of plenum pressure to ambient pressure, $\mathrm{P}_{\mathbf{0}} / \mathrm{P}_{2}$ ) and feedback tube length and volume on the operation of the flip-flop jet nozzle.

\section{EXPERIMENTAL DETAILS}

The large scale flip-flop nozzle described in Table $I$ and shown in Figure 1(a), was used only for the

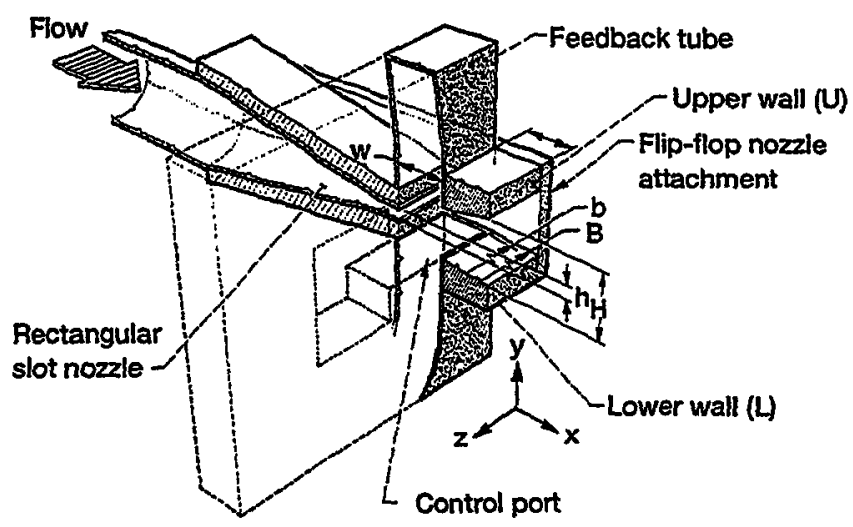

(a) Large scale.

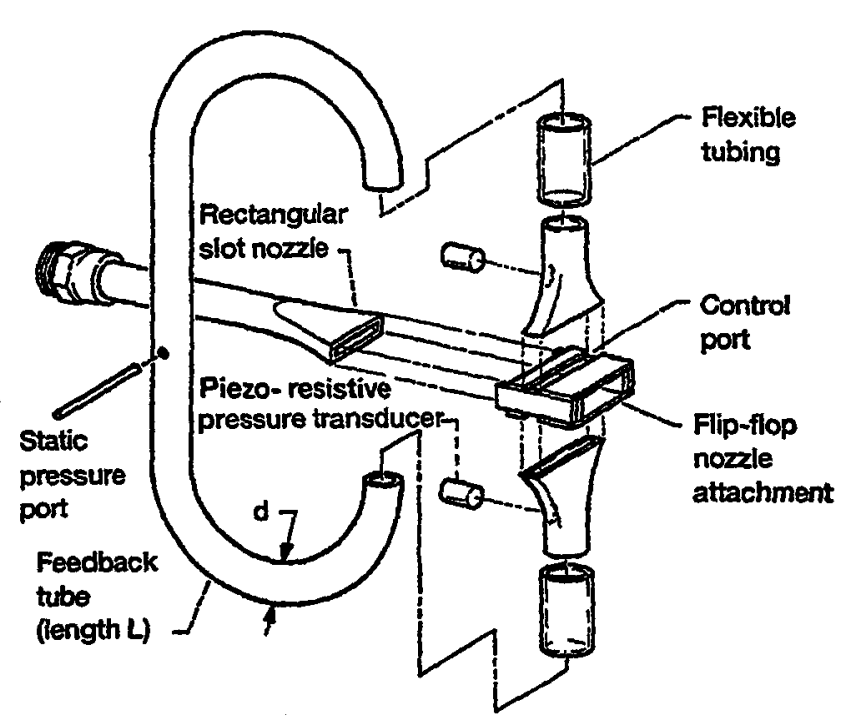

(b) Miniature scale.

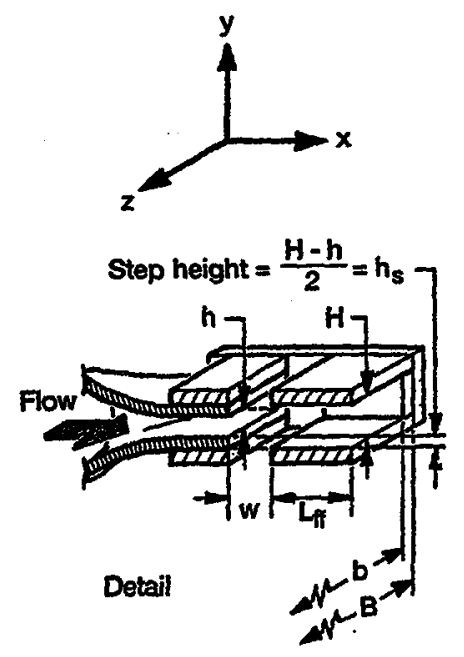

(c) Detail of miniature scale.

Figure 1.-Schematic of flip-flop nozzle. 
TABLE I DESCRIPTION OF NOZZLE PARAMETERS

\begin{tabular}{|c|c|c|c|}
\hline $\begin{array}{c}\text { NOZZLE } \\
\text { PARAMETER }\end{array}$ & SYMBOL & $\begin{array}{c}\text { LARGE SCALE } \\
\text { NOZZLE } \\
\text { DIMENSION } \\
\text { (mm, cubic } \mathrm{mm})\end{array}$ & $\begin{array}{c}\text { MINLATURE } \\
\text { NOZZLE } \\
\text { DIMENSIONS } \\
(\mathrm{mm}, \text { cubic } \mathrm{mm})\end{array}$ \\
\hline $\begin{array}{l}\text { Smaller Dimension } \\
\text { of Inner Nozzle }\end{array}$ & $\mathrm{h}$ & 6.35 & 2.34 \\
\hline $\begin{array}{l}\text { Larger Dimension } \\
\text { of Inner Nozzle }\end{array}$ & b & 69.85 & 19.05 \\
\hline Aspect Ratio (b/h) & $s$ & 11.00 & 8.15 \\
\hline $\begin{array}{l}\text { Smaller Dimension of } \\
\text { Flip-Flop Attachment }\end{array}$ & $\mathrm{H}$ & 26.98 & 7.00 \\
\hline $\begin{array}{l}\text { Larger Dimension of } \\
\text { Flip-Flop Attachment }\end{array}$ & B & 69.85 & 19.05 \\
\hline Aspect Ratio (B/H) & $\mathrm{s}$ & 2.58 & 2.72 \\
\hline $\begin{array}{l}\text { Width of } \\
\text { Feedback Slot }\end{array}$ & w & 25.40 & 3.17 \\
\hline $\begin{array}{l}\text { Axial Dimension of } \\
\text { Flip-Flop Attachment }\end{array}$ & $\mathrm{L}_{\text {ff }}$ & 25.40 & 15.87 \\
\hline $\begin{array}{l}\text { Length of } \\
\text { Feedback Tube }\end{array}$ & $\mathrm{L}$ & 444.50 & $304.8-1625.6$ \\
\hline $\begin{array}{l}\text { Diameter of } \\
\text { Feedback Tube }\end{array}$ & d & $43.88\left(\mathrm{~d}_{\mathrm{e}}\right)$ & $9.5-19.1$ \\
\hline $\begin{array}{l}\text { Volume of } \\
\text { Feedback Tube } \\
\end{array}$ & Vol & 672,194 & $21,604-465.596$ \\
\hline Nozzle Pressure Ratio & NPR & $\begin{array}{c}\text { Flow Visualization } \\
\text { Only }\end{array}$ & $1.3-2.0$ \\
\hline Exit Geomentry & - & $\begin{array}{l}\text { Divergent Walls } \\
3.6^{\circ} \text { Half Angle }\end{array}$ & $\begin{array}{l}\text { Divergent Walls } \\
5^{\circ} \text { Half Angle }\end{array}$ \\
\hline
\end{tabular}

flow visualization study. For the parametric study, a miniature nozzle (Figure 1(b) and 1(c)) was used. The nozzle has three parts: the convergent rectangular slot nozzle, a nozzle attachment with control ports, and a feedback tube that connects the control ports. The exit (center) of the inner rectangular nozzle is the origin of the coordinate system shown in Figure 1(a). The facility and nozzle were previously described in detail by Raman et al. (1993), therefore only a brief description is given here. Figure 2 shows smoke flow visualization photographs of the flip-flop jet. The visualization was carried out at very low speeds $(\sim 10 \mathrm{~m} / \mathrm{s})$ and was made possible by filling the plenum chamber with smoke and illuminating the flowfield with bright continuous light $(750 \mathrm{~W})$. The still pictures cover an axial extent of up to $\mathrm{x} / \mathrm{h}=$ 25 and show the two phases of oscillation of the jet. During phase 1 , the jet is attached to the bottom wall and during the other phase to the top wall. The details of the operation of such nozzles will be discussed in a later section.

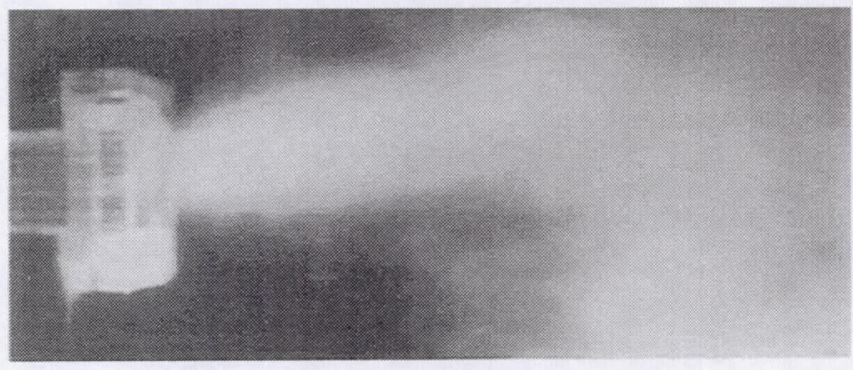

(a) Phase 1 of oscillation.

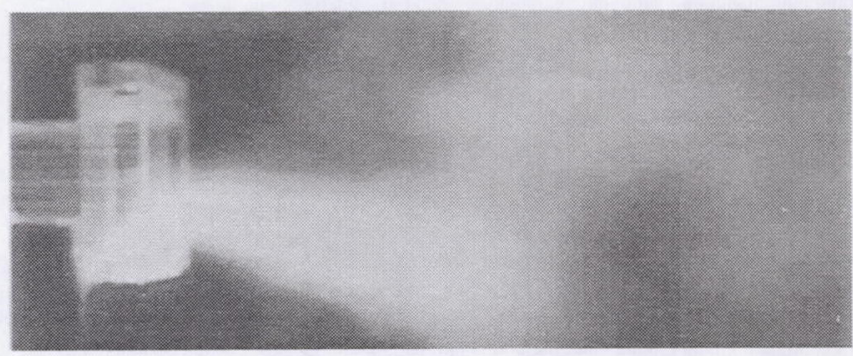

(b) Phase 2 of oscillation.

Figure 2.-Flow visualization of the two phases.

\section{RESULTS AND DISCUSSION FLOWFIELD CHARACTERISTICS}

Figure 3(a) shows the mean velocity contours in the flip-flop jet flow-field. In Figure 3(a) the mean velocity is expressed as a fraction of the jet's exit velocity. It is to be noted that the potential core is virtually absent due to the oscillation of the jet in the transverse direction. The total velocity fluctuations in the jet are shown in Figure 3(b). The velocity fluctuation level in the contour plot is expressed as a percentage of the jet exit velocity. The velocity fluctuations shown in Figure 3(b) include the coherent oscillations due to the flapping of the jet as well as randomly occurring velocity fluctuations attributed to fine scale turbulence. The coherent velocity fluctuations could be occurring at the flapping frequency and at its harmonics. Figure 4(a) shows the coherent fluctuating velocity level in the flip-flop jet phase averaged at the flapping frequency of the jet. This measurement was obtained by holding one hot-film probe stationary near the jet exit and traversing a second hot-film probe over the entire flowfield. From Figure 4(a) it can be seen that very high coherent fluctuation levels can be obtained 


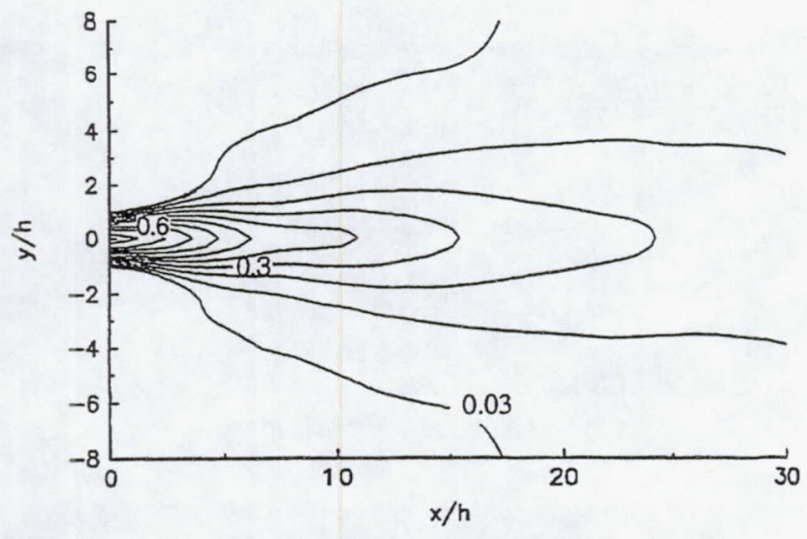

(a) Mean velocity contours $\bar{U} / \bar{U}_{e}$.

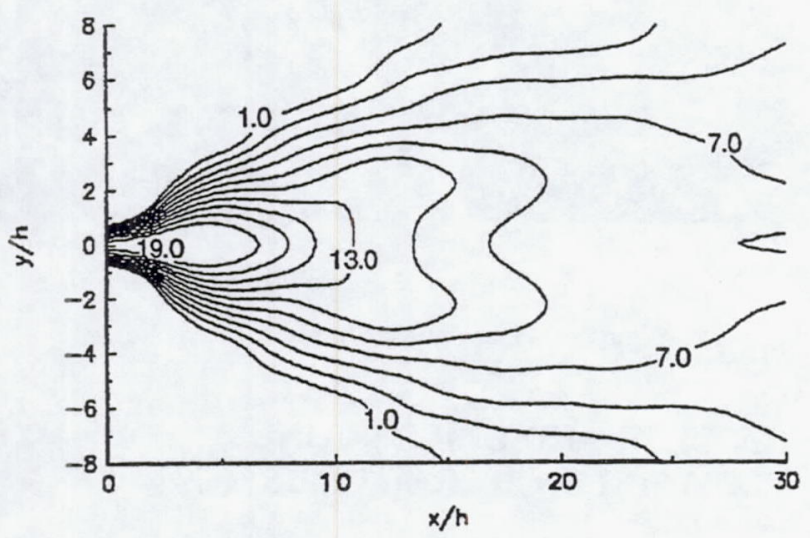

(b) Total fluctuating velocity u'/ $\overline{\mathrm{U}}_{e}(\%)$.

Figure 3.-Characterization of the flow-field of a flip-flop jet.

even far downstream from the jet's exit. It is this feature of the flip-flop jet that makes it attractive for use as an excitation device in practical flows. Figure 4(b) shows the relative phase between the stationary probe and the traversed probe. It is clear that events occurring on either side of the jet are 180 degrees out of phase. This is proof that the flapping persists even at downstream stations.

\section{OBSERVATIONS ON THE MECHANISM OF OPERATION}

As mentioned earlier when the jet from the inner nozzle (see Figure 1(b)) exhausts into the region between the two plates of the flip-flop attachment, a small pressure gradient could cause the jet to attach (or detach) from either wall. With the help of the feedback tube this process is repeated. An explanation for the operation of such nozzles based on wave propagation in the feedback tube was first

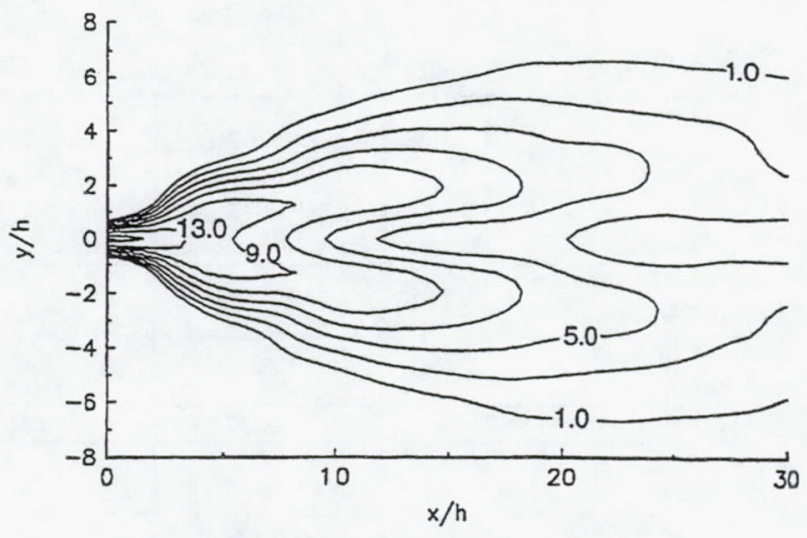

(a) Coherent fluctuating velocity $\tilde{u} / \bar{U}_{\theta}(\%)$.

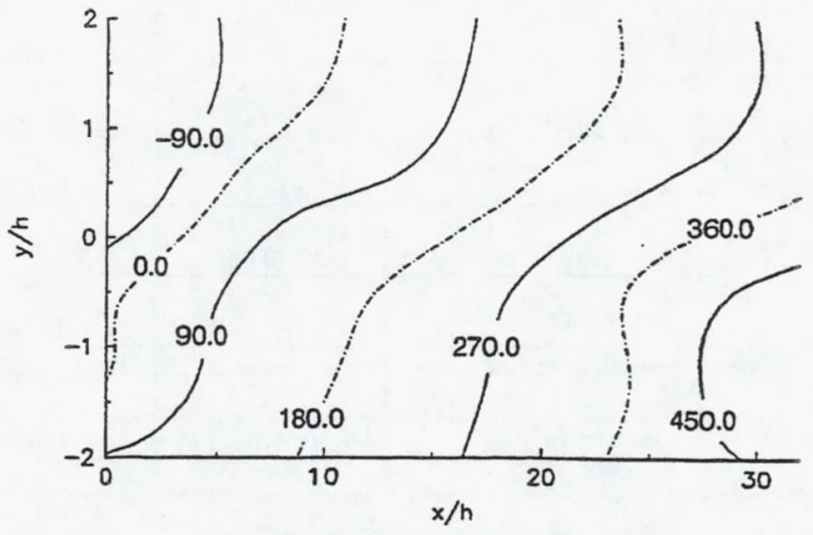

(b) Relative phase contours.

Figure 4.-Characterization of velocity fluctuations at the frequency of oscillation of the flip-flop jet.

provided by Viets (1975). However, his paper also stated that such an explanation would not be adequate for short feedback tubes. The frequencies of oscillation measured in the present work, however, are much lower than the frequencies expected based on the length of the feedback tube and the speed of propagation of pressure waves (sound) in the feedback tube. This suggests that for the lengths used in the present work the phenomenon is not controlled only by wave propagation. This also indicates that additional processes would have to be considered in order to provide a complete explanation of the operation of the flip-flop jet nozzle. In this context it needs to be mentioned that Viets et al. (1975a) did indicate that the volume of the feedback tube could be a factor, but their work did not attempt to assess the influence of this factor, nor did they document the volumes of the feedback tubes used in their work. 


\section{RELATIONSHIP BETWEEN EVENTS IN THE FEEDBACK TUBE AND IN THE SHEAR LAYER}

Figure 5 shows flow visualization photographs of the events at the nozzle exit. Smoke is injected near the nozzle lip using an external tube. The two phases shown in Figures 5(a) and 5(b) correspond

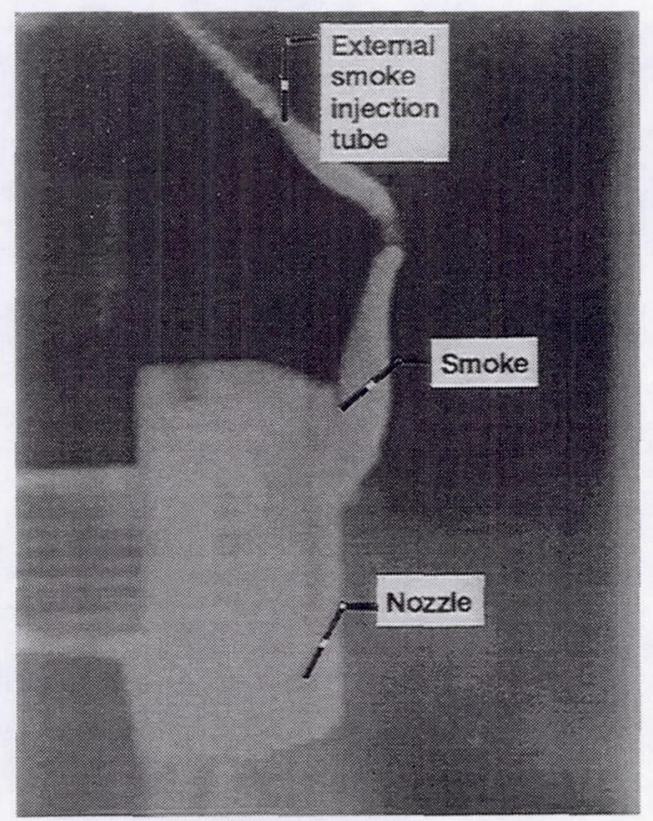

(a) Smoke being drawn into the nozzle at the top.

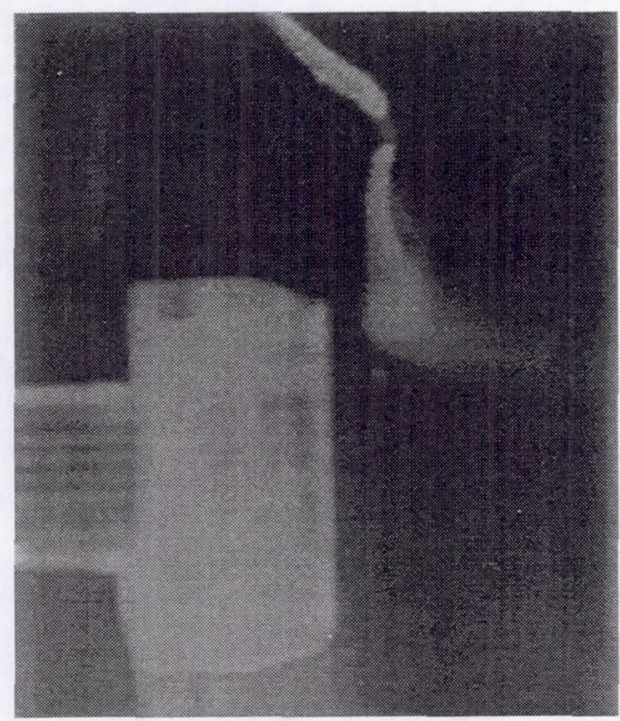

(b) Smoke being blown away from the nozzle at the top. Figure 5.-Flow visualization of events at the nozzle exit. to the two phases of jet oscillation shown in Figures 2(a) and 2(b). Figure 5(a) shows smoke being drawn into the nozzle when the jet in 2(a) is attached to the bottom and 5(b) shows smoke being blown away when the jet in 2(b) flips to the top.

The unsteady pressure time traces measured on either side of the feedback tube displayed a sinusoidal shape with a pressure difference of about $14.2 \mathrm{kPa}$ at a nozzle pressure ratio of 1.8 . When the jet was attached to the lower wall, the absolute pressure at that control port was measured to be $53.25 \mathrm{kPa}$, while the corresponding pressure at the other port was $67.45 \mathrm{kPa}$. Since the two control ports are connected by the feedback tube, the equalization of pressure occurs by a certain mass of fluid being drawn in through port 2 (shown by the inflow of smoke into the nozzle in Figure 5(a)). The equalization of pressure causes the jet to detach from the lower wall and attach to the upper wall (Shown by smoke being blown away near the upper wall in Figure 5(b)). The process then repeats itself.

In an attempt to visualize the events within the feedback tube, another experiment was performed. The feedback tube (metal) was replaced with a transparent tygon tube with a small column of alcohol in the tube. When the flip-flop nozzle was run in this condition, the column of alcohol was visually seen to oscillate at the frequency at which the jet flapped. As the nozzle pressure ratio was increased the oscillation frequency of the column of alcohol increased and so did its amplitude of oscillation (displacement of the alcohol column from its equilibrium position). It should be noted here that while the frequency of oscillation of the alcohol column is an indication of the frequency of flapping of the jet, the amplitude of oscillation is an indication of the volume of air that is alternately being pumped from one side to another during alternate pressure equalization. Although the trends were clear, it was not possible to keep track of the change of frequency and changes in the amplitude of oscillation of the alcohol column for small changes in nozzle pressure ratio. Therefore all the observations should be interpreted with caution and treated as qualitative. It should be pointed out that at a given nozzle pressure ratio, the nozzle with 
alcohol in the feedback tube oscillated at a lower frequency than the nozzle with no alcohol in the feedback tube. Although the alcohol does interfere with the process, it at least provides a qualitative picture of what is happening.

Figure 6(a) shows a spectrum from a hot-film probe located near the jet exit shear layer. The hot-film was positioned at the transverse location where the maximum velocity fluctuation was recorded. Figure 6 (b) shows a spectrum from the piezoresistive pressure transducer in the feedback tube. Figure 6(a) and 6(b) represent simultaneous averaged spectra of velocity oscillations in the shear layer and of pressure oscillations in the feedback tube. In both measurements the same dominant frequency (f)

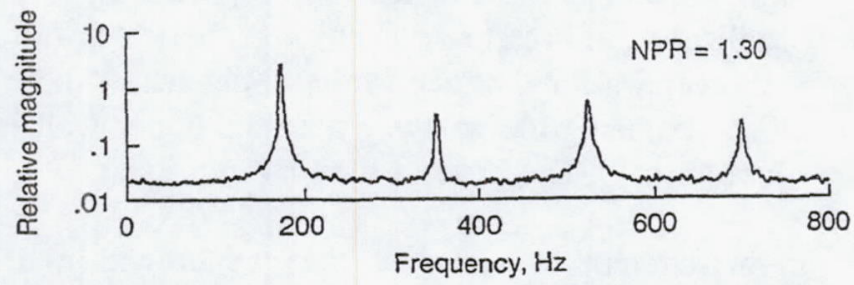

(a) Spectrum of unsteady velocity measured in the shear layer at the jet exit.

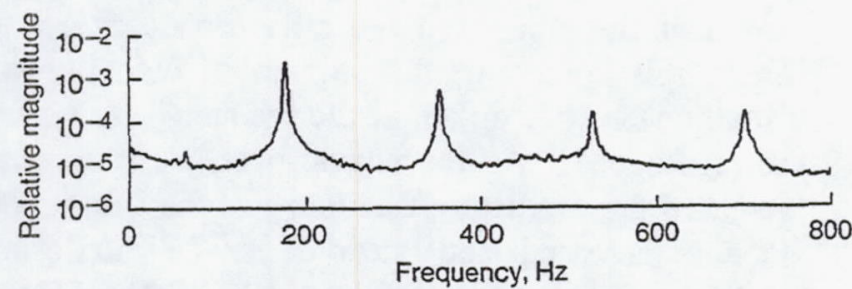

(b) Spectrum of pressure oscillations measured in the feedback tube.

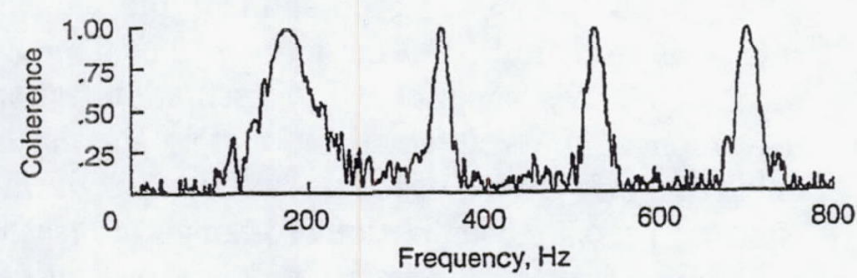

(c) Linear spectral coherence function.

Figure 6.-Velocity and pressure spectra.

and three harmonics (2f, $3 f$, and $4 f$ ) were observed. Figure $6(\mathrm{c})$ represents the linear spectral coherence between the two signals. At $f$ and its harmonics the linear spectral coherence is almost 1.00 . This

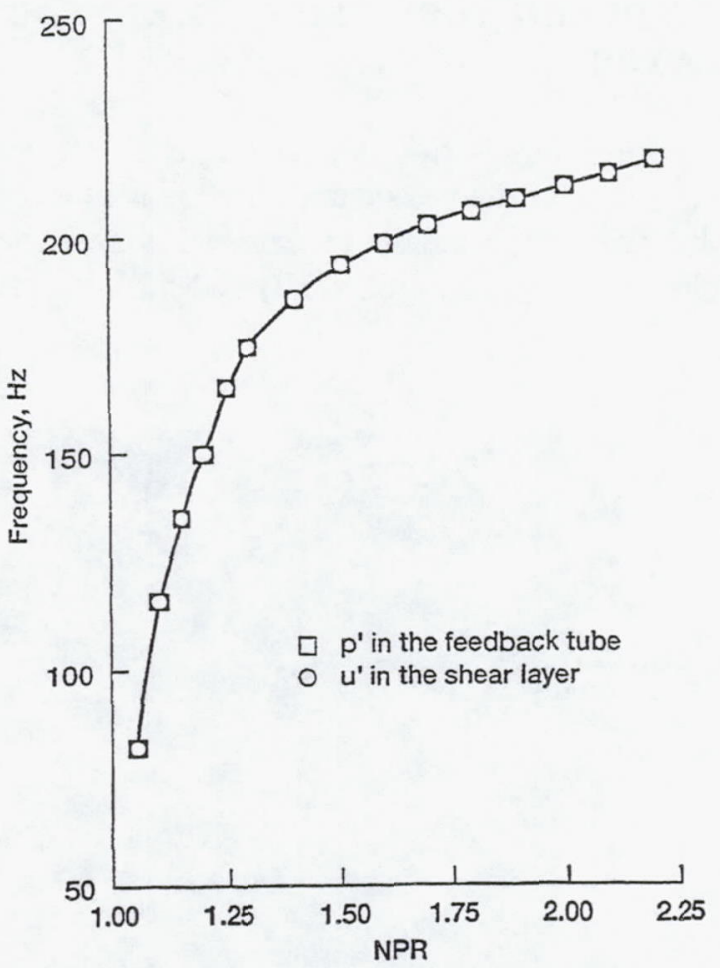

(a) Frequency of oscillation versus nozzle pressure ratio.

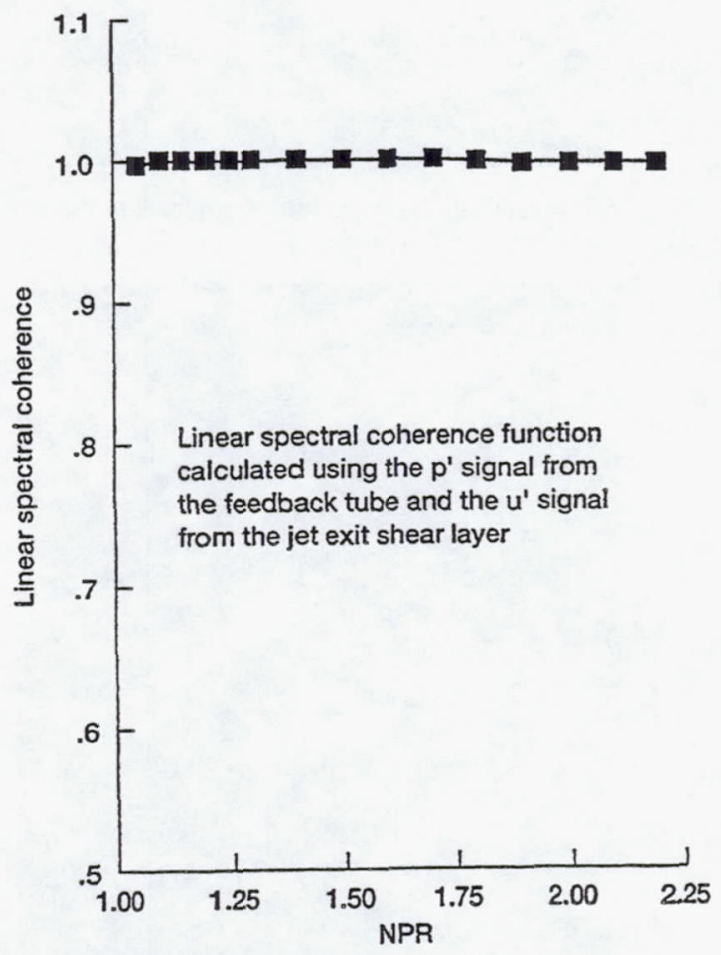

(b) Linear spectral coherence versus nozzle pressure ratio.

Figure 7.-Relationship between pressure oscillations in the feedback tube and velocity perturbations in the shear layer at various nozzle pressure ratios. 
indicates that the velocity fluctuations in the jet's shear layer are highly correlated to the pressure oscillations in the feedback tube.

Figure 7(a) shows a plot of the frequency of oscillation of the flip-flop jet versus NPR. The frequency of oscillation obtained from the unsteady pressure signal in the feedback tube was seen to be the same as that obtained from the hot-film measurements in the shear layer of the jet. In addition, the linear spectral coherence at the oscillation frequency (Figure 7(b)) between the two signals was 1.0 indicating a strong correlation between the pressure signals in the feedback tube and the coherent velocity signals in the jet's shear layer.

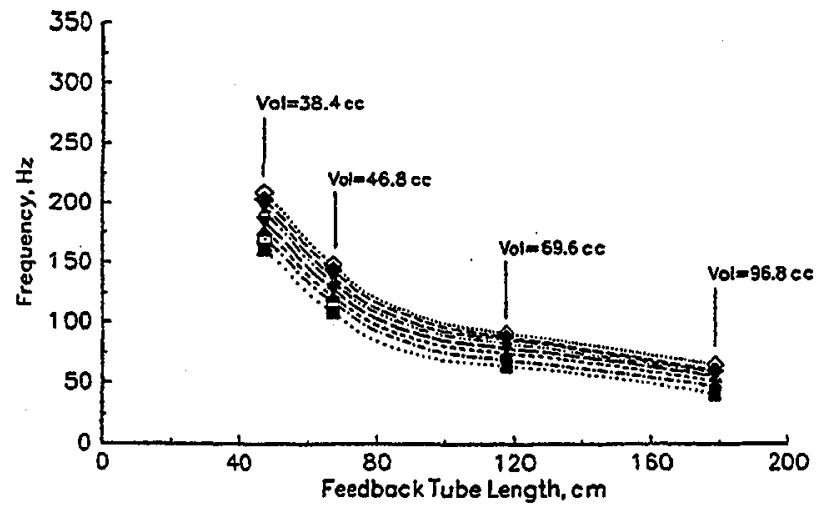

(a) Feedback tube diam $=0.754 \mathrm{~cm}$.

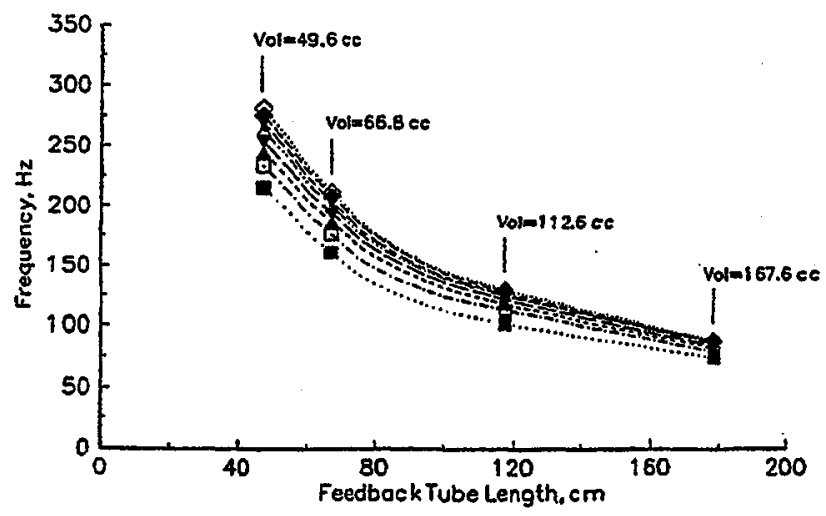

(b) Feedback tube diam $=1.072 \mathrm{~cm}$.

\section{EFFECT OF VARYING NOZZLE PARAMETERS ON THE FREQUENCY OF OSCILLATION.}

The operation of the flip-flop jet nozzle depends on a multitude of parameters. It is impractical to vary each of those parameters while keeping the others constant. The present work only attempts to vary a limited set of parameters which are believed to be important for the operation of this device. These important parameters are the nozzle pressure ratio, as well as the feedback tube length and volume.

A case where both length and volume of the feedback tube are varied simultaneously is shown in Figure 8(a-d). To obtain the data for this case the feedback tube length was varied for a constant diameter tube. An increase in the length also automatically increased the volume. Note that in

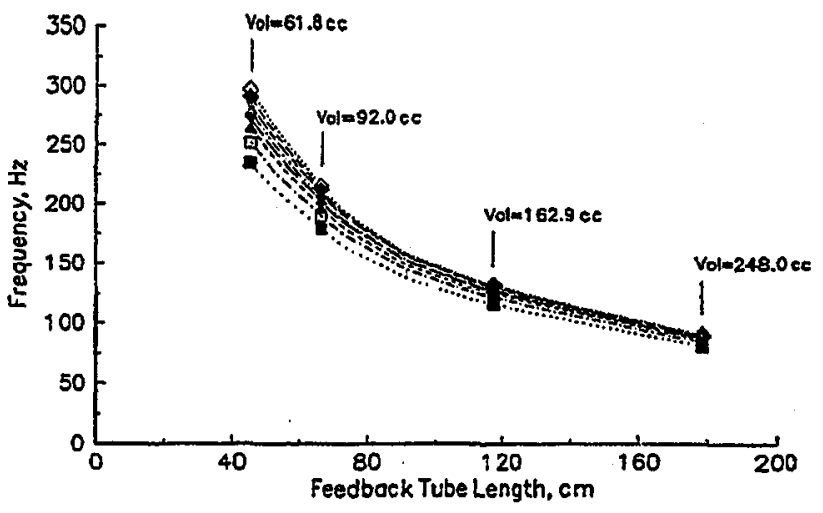

(c) Feedback tube diam $=1.334 \mathrm{~cm}$.

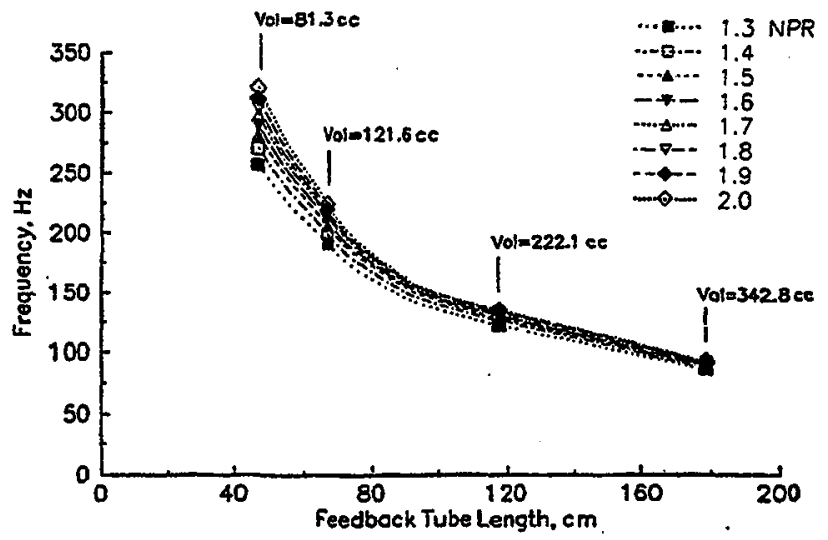

(d) Feedback tube diam $=1.588 \mathrm{~cm}$.

Figure 8.-Effect of simultaneous variation of length and volume of the feedback tube. 
Figure 8(a-d) the volume and length do not directly relate using the diameter given. This is due to the noncircular cross section of the feedback tube where it connects to the control port (see Figure 1(b)). The frequency of oscillation of the flip-flop jet is seen to decrease with an increase in the length of the constant diameter tube. The frequency of oscillation was also seen to increase with increase in the nozzle pressure ratio.

The variation of the oscillation frequency versus feedback tube length for constant feedback tube volumes is shown in Figure 9(a-d) for various nozzle pressure ratios. In order to keep the volume constant for the various feedback tube lengths, feedback tubes of smaller diameters had to be used for longer lengths. When the length was increased at a constant volume, the frequency of oscillation was seen to decrease. This observation can be

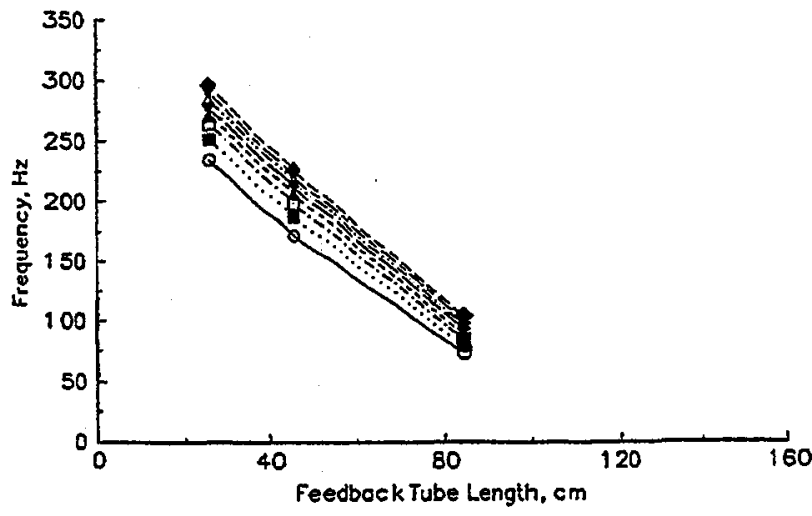

(a) Feedback tube volume $=62 \mathrm{cc}$.

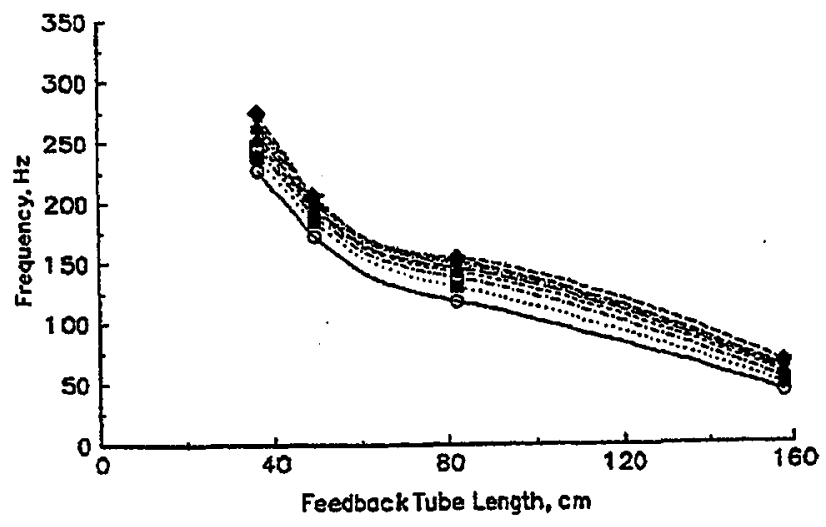

(b) Feedback tube volume $=95 \mathrm{cc}$. rationalized by noting that with a longer tube it takes a longer time for the pressures between the two ports to equalize. Again, higher nozzle pressure ratios resulted in higher frequencies of oscillation.

The variation of the oscillation frequency versus feedback tube volume for constant length feedback tubes is shown in Figure 10 for various nozzle pressure ratios. In order to keep the length constant for various feedback tube volumes, feedback tubes of various diameters were used. For a constant length, the frequency of oscillation increased as the volume of the feedback tube was increased. It appears that the greater cross-sectional area of the feedback tube lowers the resistance to the pressure equalization process in the feedback tube. The time for the equalization of the pressure is therefore much shorter, resulting in higher frequencies of oscillation. The frequency of oscillation increases as the NPR increases for the constant feedback tube length case (with volume varying).

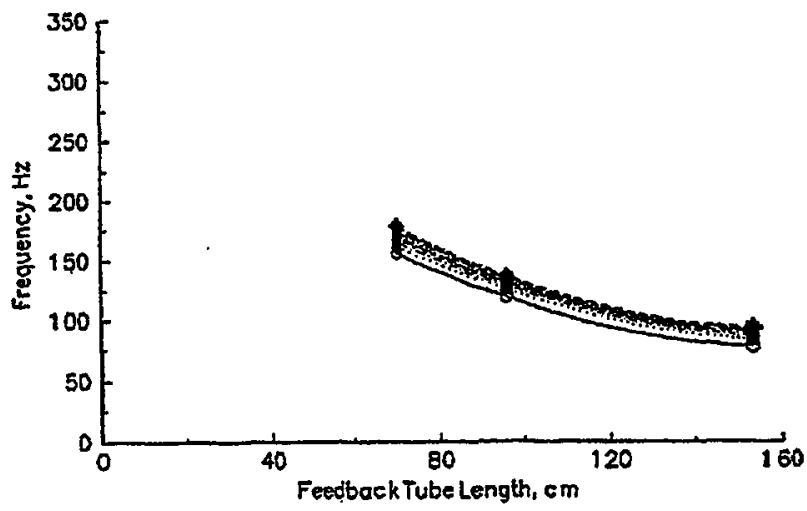

(c) Feedback tube volume $=160 \mathrm{cc}$

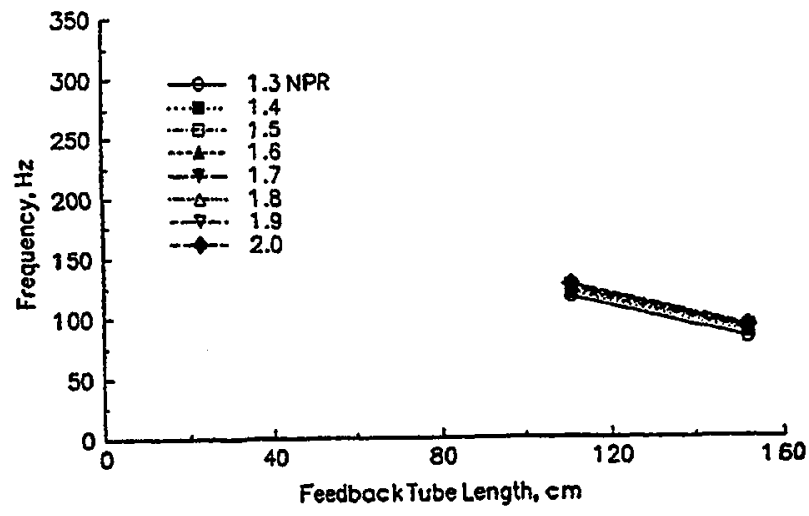

(d) Feedback tube volume $=240 \mathrm{cc}$.

Figure 9.-Effect of length of feedback tube with volume constant. 
It is to be noted that a limited attempt was made to present the data in a universal non-dimensional form. However, the non-dimensional model did not collapse all the data points. The dimensional data documented in this paper would still be valuable for future modeling of this device.

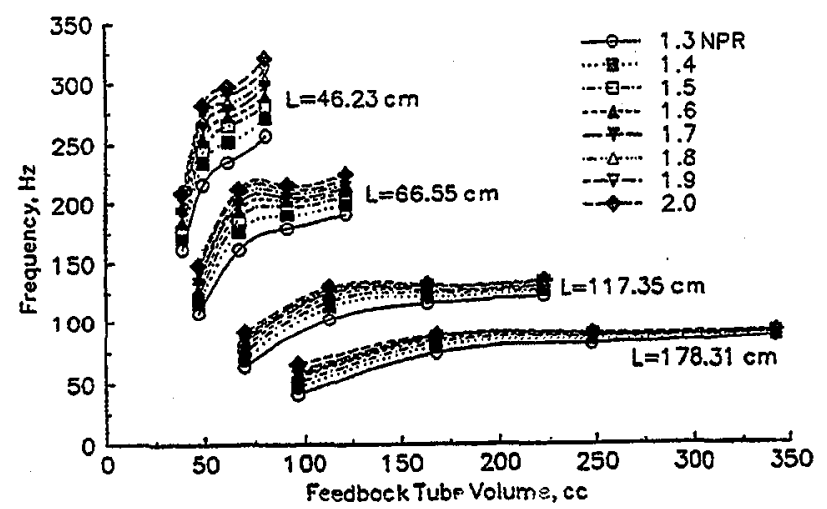

Figure 10.-Effect of feeciback tube volume with length constant.

\section{EFFECT OF VARYING NOZZLE PARAMETERS ON THE COHERENT EXCITATION LEVELS}

The evaluation of the flip-flop jet nozzle as an excitation device would not be complete without a careful documentation of the coherent velocity perturbation levels capable of being produced by this device. In order to quantify these levels a hotfilm probe was positioned at various downstream stations and the maximum coherent velocity perturbation level was recorded. The effect of the feedback tube length and volume, as well as the effect of the nozzle pressure ratio (NPR), will be discussed next. It is important to note that an overall picture of the coherent velocity field produced by the flip-flop jet was shown in Figure 4(a) for one set of conditions. However, that jet was operated at a very low nozzle pressure ratio $(\mathrm{NPR}=1.02)$. Since it is impractical to collect data similar to that presented in Figure 4(a) for several feedback tube lengths, volumes and nozzle pressure ratios, only the maximum coherent velocity perturbation level at three different axial stations was obtained.

Figure 11(a) shows a plot of the peak coherent velocity perturbation level versus feedback tube length for a constant feedback tube volume of $95 \mathrm{cc}$. It can be seen that the velocity perturbation levels are around $35 \%$ at $\mathrm{x} / \mathrm{h}=7$, around $20 \%$ at $\mathrm{x} / \mathrm{h}=$ 16 , and around $15 \%$ at $x / h=32$. It appears that at low feedback tube lengths the effect of varying the NPR is not so significant whereas at a feedback tube length of $175 \mathrm{~cm}$ there is a considerable effect of the NPR on the coherent velocity perturbation levels.

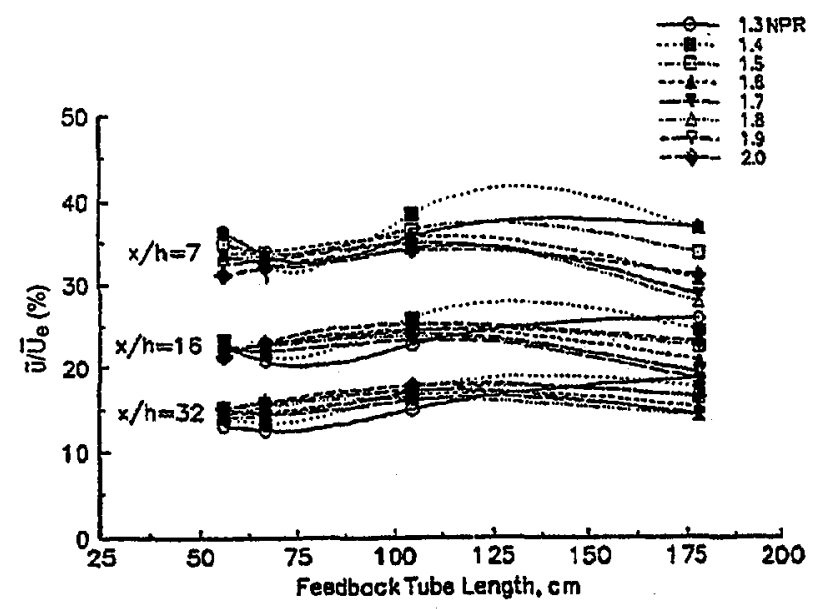

(a) Eifect of feedback tube length for a constant volume of $95 \mathrm{cc}$.

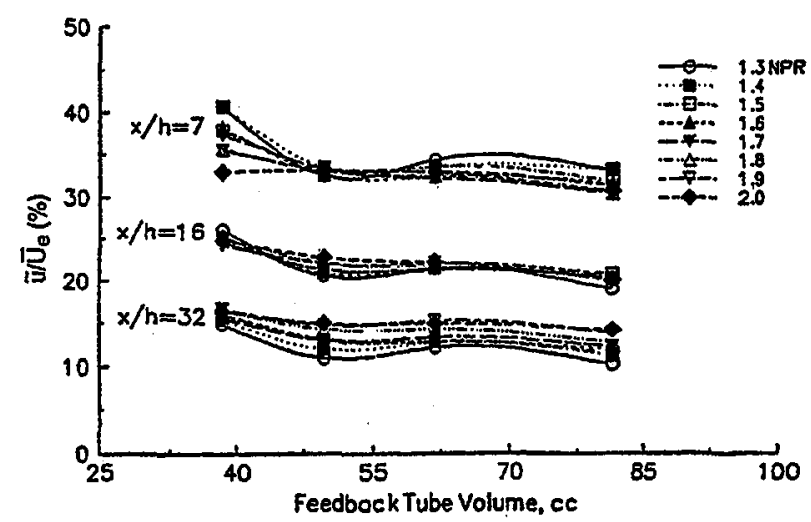

(b) Effect of feedback tube volume for a constant length of $46.23 \mathrm{~cm}$. Figure 11.-Effect of varying nozzle parameters on coherent velocity perturbation levels. 
Figure 11(b) shows data similar to that discussed in Figure 11(a). However, the effect of varying the feedback tube volume at a constant feedback tube length is addressed here. The coherent velocity perturbation levels are of the same order as discussed in connection with Figure 11(a) at the three axial stations. There appears to be no significant variation with volume or with nozzle pressure ratio. The conclusions to be made from Figures 11(a) and 11(b) are that the magnitude of the normalized coherent velocity perturbation levels that could be produced by the flip-flop jet excitation device depend mainly on the axial location at which the levels are measured. There is no significant change with feedback tube length or volume. There is a limited dependence on NPR at large feedback tube lengths. It should be emphasized that these observations are in contrast to the observations for the frequency of oscillation of the flip-flop jet. The frequency of oscillation depended considerably on the feedback tube length, volume and the nozzle pressure ratio.

\section{ESTIMATES OF MEASUREMENT UNCERTAINTY}

Some estimates for the uncertainty in the measurements were provided in an earlier paper (Raman and Rice (1993)). The estimates were obtained using the methods described by Moffat (1985). For the piezoresistive pressure transducers the calibration uncertainty was $1.5 \%$ and the first order uncertainty was $0.3 \%$, yielding a total uncertainty of $1.53 \%$. Since the same pressure transducers were used under similar conditions in the present work, the earlier estimates are valid here.

In addition, the present work used hot-film probes. For the single component film probes the calibration uncertainty was $1-2 \%$ and the first order uncertainty was $\leq 0.5 \%$. However, when the probe was placed in the oscillating flowfield of the flip-flop jet the errors were much larger. Near the nozzle exit there is an alternate forward and backflow as described in connection with Figure 5. The hot-film probe cannot distinguish between forward and backward flow and therefore the results near the jet exit $(x / h<5)$ are not accurate. With the exception of Figures 3 and 4 this region has been avoided.

\section{CONCLUDING REMARKS}

The flip-flop jet nozzle was evaluated for use as an excitation device for the control of practical shear flows. The effect of the important nozzle parameters, i.e., the feedback tube length and volume as well as the nozzle pressure ratio on the frequency of oscillation as well as the coherent velocity perturbation levels was investigated. It was found that the frequency of oscillation of the flipflop jet depended significantly on the feedback tube length and volume as well as the nozzle pressure ratio. In contrast the coherent normalized velocity perturbation level did not depend on the above parameters. The data presented in this paper would be valuable for future modeling of this device.

In summary, when the flip-flop jet nozzle is used as an excitation device the nozzle parameters need to be carefully selected so that the frequency of oscillation of the flip-flop jet matches that of the natural instability of the flow being excited. However, the coherent normalized velocity perturbation levels that this device is capable of producing are by far independent of the nozzle parameters and depend only on the location at which these are measured. If one desires higher velocity perturbation levels, then the flip-flop jets would have to be located closer to (or built into) the primary flow being excited. As a final note, the velocity perturbation levels that the flip-flop device is capable of producing are far greater than the levels produced using conventional excitation sources. Future research within our group at NASA Lewis Research Center will focus on applying these devices for the control of practical shear flows.

\section{ACKNOWLEDGEMENTS}

The experiments reported in this paper were done when the first author was with Sverdrup Technology, Inc. The authors would like to thank Dr. B. Wendt and Dr. H. Viets and Mr. John M. Abbott for providing suggestions and for their 
encouragement. In addition, the authors would like to thank Ms. Tammy Langhals for her help in the production of this document.

\section{REFERENCES}

Ahuja, K.K., and Brown, W.H., 1989, "Shear Flow Control by Mechanical Tabs," AIAA Paper 89-0994.

Ahuja, K.K., Lepicovsky, J., Tam, C.K.W., Morris, P.J., and Burrin, R.H., 1982, "Toneexcited Jets, Theory and Experiments, "NASA CR3538.

Beale, R.B., and Lawyer, M.T., 1974, "Development of a Wall-Attachment Fluidic Oscillator Applied to Volume Flow Metering," In Flow-its measurement and control in science and industry, Vol. 1, Part II, pp. 989-996, Edited by Dowdell, R.B., Instrument Society of America.

Brown, W.H., and Ahuja, K.K., 1990, "Jet Mixing Enhancement by Hydrodynamic Excitation," AIAA Paper 90-4005.

Crow, S.C., and Champagne, F.H., 1971, "Orderly Structure in Jet Turbulence," Journal of Fluid Mechanics, Vol. 48, pp. 547-591.

Davis, M.R., 1982, "Variable Control of Jet Decay," AIAA Journal, Vol. 20, pp. 606-609.

Hill, W.G., and Greene, P.R., 1977, "Increased Turbulent Jet Mixing Rates Obtained by SelfExcited Acoustic Oscillations," ASME Journal of Fluids Engineering, Vol. 99, pp 520-525.

Moffat, R.J., 1985, "Using Uncertainty Analysis in the Planning of an Experiment," ASME Journal of Fluids Engineering, Vol. 107, pp. 173-178.

Morris, G.J., Jurewicz, J.T., and Palmer, G.M., 1992, "Gas-Solid Flow in a Fluidically Oscillating Jet," ASME Journal of Fluids Engineering, Vol. 114, pp. 362-366.

Morris, N.M., 1973, "An Introduction to Fluid Logic," McGraw Hill Book Co., (UK).

Parekh, D.E., Reynolds, W.C., and Mungal, M.G., 1987, "Bifurcation of Round Air Jets by Dual-Mode Acoustic Excitation," AIAA Paper 870164.

Raman, G., Hailye, M., and Rice, E., 1993, "Flip-Flop Jet Nozzle Extended to Supersonic Flows," AIAA Journal, Vol. 31, No. 6, pp. 10281035.
Raman, G., and Rice, E.J., 1991, "Axisymmetric Jet Forced by Fundamental and Subharmonic Tones," AIAA Journal, Vol. 29, pp. 1114-1122.

Raman, G., and Rice, E.J., 1993, "Development of Phased Twin Flip-Flop Jets,", ASME Paper 93WA/NCA-25.

Rice, E.J., and Raman, G., 1993, "Enhanced Mixing of a Rectangular Supersonic Jet by Natural and Induced Screech," AIAA Paper 93-3263.

Schreck, S., 1992, "Application of a Flip-Flop Nozzle on Plume Mixing Enhancement," Presented at the First NASA/Industry High Speed Research, Nozzle Symposium, NASA LeRC, Cleveland OH, (to be published as a NASA CP).

Strykowski, P.J., Krothapalli, A., and Wishart, D., 1992, "The Enhancement of Mixing in High Speed Heated Jets Using a Counterflowing Nozzle," AIAA Paper 92-3262.

Tokaty, G.A., 1971, "A History and Philosophy of Fluid Mechanics," G.T. Foulis and Co. Ltd. (UK).

Viets, H., 1975, Flip-Flop Jet Nozzle," AIAA Journal, Vol. 13, pp 1375-1379.

Viets, H., Blaster, D., Toms, H.L. Jr., 1975a, "Time Dependent Fuel Injectors," AIAA Paper 751305.

Viets, H., Blaster, D., and Toms, H.L. Jr., 1975b, "Feasibility study of Unsteady Foam Generators, " DOD-AGFSRS-75-6, Wright-Patterson Air Force Base.

Warren, R.W., 1962, "Some Parameters Affecting the Design of Bistable Fluid Amplifiers," Symposium on Fluid Jet Control Devices at the Winter Annual Meeting of the ASME, New York.

Wiltse, J.M., and Glezer, A., 1993, "Manipulation of Free Shear Flows using Piezoelectric Actuators," Journal of Fluid Mechanics, Vol. 249, pp. 261-285.

Zaman, K.B.M.Q., Reeder, M.F., and Samimy, M., 1994, "Control of an Axisymmetric Jet Using Vortex Generators," Physics of Fluids, Vol. 6(2), pp. 778-793. 
Public reporting burden for this collection of information is estimated to average 1 hour per response, including the time for reviewing instructions, searching existing data sources, gathering and maintaining the data neoded, and completing and reviewing the collection of information. Send comments regarding this burden estimate or any olher aspect of this Davis Highway, Suite 1204, Arlington, VA 22202-4302, and to the Office of Management and Budget, Paperwork Reduction Project (0704-0188), Washington, DC 20503.
1. AGENCY USE ONLY (Leave blank)
2. REPORT DATE
April 1994
3. REPORT TYPE AND DATES COVERED
Technical Memorandum

4. TITLE AND SUBTITLE

5. FUNDING NUMBERS

Evaluation of Flip-Flop Jet Nozzles for Use as Practical Excitation Devices

6. AUTHOR(S)

WU-505-62-52

Ganesh Raman, Edward J. Rice, and David M. Cornelius

8. PERFORMING ORGANIZATION REPORT NUMBER

National Aeronautics and Space Administration

Lewis Research Center

E-8190

Cleveland, Ohio 44135-3191

10. SPONSORINGMONITORING AGENCY REPORT NUMBER

National Aeronautics and Space Administration

Washington, D.C. 20546-0001

NASA TM-106377

11. SUPPLEMENTARY NOTES

Prepared for ASME Fluids Engineering Division Summer Meeting sponsored by the American Society of Mechanical Engineers, Lake Tahoe, Nevada, June 19-23, 1994. Ganesh Raman, NYMA, Inc., Engineering Services Division, Brook Park, Ohio 44142 (work funded by NASA Contract NAS3-27186); Edward J. Rice, NASA Lewis Distinguished Research Associate, retired; David M. Comelius, Stanford University, Stanford, California 94305 and Summer Student Intern at NASA Lewis Research Center. Responsible person, Ganesh Raman, organization code 2660, (216) $433-3607$.

12a. DISTRIBUTIONAVAILABILITY STATEMENT 12b. DISTRIBUTION CODE

Unclassified -Unlimited

Subject Category 02

13. ABSTRACT (Maximum 200 words)

This paper describes the flowfield characteristics of the flip-flop jet nozzle and the potential for using this nozzle as a practical excitation device. It appears from the existing body of published information that there is a lack of data on the parameters affecting the operation of such nozzles and on the mechanism of operation of these nozzles. An attempt is made in the present work to study the important parameters affecting the operation and performance of a flip-flop jet nozzle. Measurements were carried out to systematically assess the effect of varying the nozzle pressure ratio (NPR) as well as the length and volume of the feedback tube on the frequency of oscillation of this device. Flow visualization was used to obtain a better understanding of the jet flowfield and of the processes occurring within the feedback tube. The frequency of oscillation of the flip-flop jet depended significantly on the feedback tube length and volume as well as on the nozzle pressure ratio. In contrast, the coherent velocity perturbation levels did not depend on the above mentioned parameters. The data presented in this paper would be useful for modeling such flip-flop excitation devices that are potentially useful for controlling practical shear flows.

\section{SUBJECT TERMS}

Flip-flop jets; Oscillatory jets; Fluidics; Excitation devices; Shear flow control

15. NUMBER OF PAGES

13

16. PRICE CODE

$\mathrm{A} 03$

\begin{tabular}{c|c}
\hline 17. SECURITY CLASSIFICATION & 18. SECURITY CLASSIFICATION \\
OF REPORT & $\begin{array}{c}\text { OF THIS PAGE } \\
\text { Unclassified }\end{array}$ \\
Unclassified
\end{tabular}

19. SECURITY CLASSIFICATION OF ABSTRACT Unclassified 